DOI: $10.25100 /$ pfilosofica.v0i53.11374

\title{
NUSSBAUM, M. (2020). LA TRADICIÓN COSMOPOLITA. UN NOBLE E IMPERFECTO IDEAL. EDICIONES PAIDÓS
}

\author{
Por: Hans Leonardo Florián Sánchez ${ }^{1}$ \\ Pontificia Universidad Javeriana, Colombia.
}

Recibido: 8 de febrero de 2021. Aprobado: 12 de abril de 2021.

\section{Introducción}

El presente texto reconstruye las ideas centrales del argumento de la filósofa Martha Nussbaum en su más reciente obra La Tradición Cosmopolita (2020), en la cual realiza un análisis del origen del cosmopolitismo con la escuela cínica y de los amplios desarrollos de algunos representantes del estoicismo, encontrando allí el germen de algunos problemas del cosmopolitismo contemporáneo. Es por ello que la autora rescata perspectivas cosmopolitas que han sido obnubiladas, reconociendo en Grocio y Adam Smith aportes que le ayudarán a sustentar su propuesta del enfoque de las capacidades. Del primero se vale para mostrar la necesidad de cuestionar la comprensión clásica del concepto de propiedad, mientras que en el pensamiento del británico encuentra la posibilidad de demostrar la necesidad de condiciones materiales que soporten la vida humana y por las cuales se desarrollan las capacidades humanas. Finalmente, se plantean cinco problemas actuales del cosmopolitismo y encuentra en el EC una perspectiva para la tradición cosmopolita.

\section{Cosmopolitismo Estoico}

La primera mención del término cosmopolita se remonta al conocido episodio en el cual Diógenes "El cínico" es interrogado acerca de su proveniencia, pues es bien sabido que este fue exiliado de Sinope y se

\footnotetext{
${ }^{1}$ Hans Leonardo Florián Sánchez cursa actualmente estudios de doctorado en la Pontificia Universidad Javeriana. Licenciado en Filosofía, egresado de la Corporación Universitaria Minuto de Dios y Magister en Educación de la Universidad Militar Nueva Granada. Autor de La Ciudadanía cosmopolita emergente en los modelos de naciones unidas, capítulo de libro publicado en Pesquisas em Educação no contexto Brasil-Colombia y coautor del articulo "La ciudadanía cosmopolita como estrategia pedagógica según el modelo de naciones unidas" (2019), publicado en la Revista Signos 40(2). Sus áreas de trabajo investigativo se relacionan con filosofía moderna, cosmopolitismo y educación cosmopolita. Información de contacto.

E-mail: hans-florian@javeriana.edu.co ORCID: 0000-0001-6585-0178
} 
radicó en Atenas, de tal forma que su respuesta a la pregunta fue "una sola palabra: kosmopolitês, "ciudadano del mundo»" Diógenes Laercio, VI.63, según se cita en Nussbaum (2020). Si bien es poco el desarrollo que se puede dar a esta afirmación, se puede deducir de ella que era otra manera de demostrar que el lugar de origen, el género, la clase social son considerados como meros atributos que no tienen relevancia moral alguna. Las prácticas contraculturales cínicas ponían el énfasis en el valor de la vida y en la posibilidad de florecimiento de la capacidad racional y moral, entendidas como el conjunto de capacidades humanas para el razonamiento y la libre elección, lo que conlleva al desarrollo de la virtud y el elevado potencial humano.

Sin embargo, para realizar un rastreo histórico más profundo de esta tradición debemos remitirnos a la filosofía estoica. Dentro del planteamiento moral de esta corriente filosófica, Cicerón esboza un ser humano vinculado a dos comunidades, a saber, el vínculo local y aquel otro que se termina en los límites que el sol da a la nación; de esta segunda comunidad se derivan las obligaciones morales fundamentales por las cuales estamos vinculados a la humanidad y que conllevan a que la toma de decisiones debe enfocarse en el bien de la especie. Es decir, los planteamientos estoicos tienen como piedra angular de su ética la comprensión de la humanidad como una comunidad que se encuentra vinculada por el uso de la razón, cualidad divina dentro de lo humano y que caracteriza a las personas con un ilimitado valor moral, el cual se termina reflejando en su carácter de ciudadano.

Por otra parte, Séneca en la epístola 41 de Epístolas morales a Lucilo reitera el planteamiento ciceroniano de la vinculación a dos comunidades, aquella en la que nacemos y la colectividad humana la cual es verdaderamente pública, de la que provienen todas nuestras obligaciones morales, siendo la moralidad la forma en la que nos percibimos ligados al género humano por medio de la razón práctica moral que todos los seres humanos poseemos; por ello, nos convertimos en conciudadanos que comparten una ley común. De lo anterior se deduce que la humanidad debe ser regida por condiciones de igualdad en las que se fundamenta el respeto mutuo que ha de existir entre los seres.

Por lo tanto, el carácter de humanidad que poseemos proviene de la cualidad de la razón que dota al animal racional de la valiosa capacidad moral, por la cual se da de manera natural la lealtad con la comunidad moral humana y por la que se desprenden obligaciones legales y morales que conllevan a que el criterio para la solución de los diversos problemas sea el respeto por el otro. De esta ética se desprende una concepción de la política que comprende a la humanidad como comunidad moral capaz de 
una deliberación razonable, a la vez que reconoce la racionalidad como la cualidad divina propia de cada persona, el valor especial de cada hombre, mujer y niño; por lo anterior, la ubicación de cada ser humano es un aspecto meramente accidental en relación con su valor como miembro de esta comunidad. Es decir que desde la perspectiva estoica la política es el proceso de comprensión empática por el cual se reconoce la humanidad del otro y en ello se encuentra la existencia de un propósito común, lo que conlleva a transformar la visión clásica que se tiene sobre el enemigo político.

Es así como el cosmopolitismo helénico es una política centrada en la humanidad que reconoce la igualdad de las personas debido a su capacidad moral que los dota de dignidad. Sin embargo, esta es una idea moral que tiene repercusiones políticas que obligan a repensar las clásicas concepciones de justicia. Cicerón planteó que esta debía ser entendida como una moral trasnacional que se fundamente en el respeto por la humanidad tratando a los seres humanos como fines, de la cual se desprende la regla principal de no usar la violencia para nuestro beneficio pues ello destruye la comunidad humana; para mantener la buena relación con este vínculo primario no se debe causar daño a nadie, teniendo como única excepción el castigo cuando es necesario, por ejemplo, en el caso que no se respete la propiedad ajena pues la usurpación de la misma no es más que otra forma de ejercer violencia.

En De Officis, Cicerón plantea una diferencia entre los deberes de justicia y los de ayuda material, siendo los primeros de carácter trasnacional mientras que los segundos son relativos a las personas cercanas y queridas. Sin embargo, de acuerdo con Nussbaum (2020) los deberes de ayuda material son irrelevantes desde la concepción estoica, ello debido a su arraigada comprensión sobre los bienes materiales. Cabe recordar que para esta escuela filosófica las riquezas y comodidades no son necesarias para el objetivo de fortalecer el alma, por el contrario, estos generan corrupción de las pasiones. Para lograr la eudaimonía es necesaria la superación de las pasiones por medio de la indiferencia frente a los bienes materiales, pues se deben realzar las capacidades morales que nos convierten en seres sociales e interconectados. En relación con estos deberes de segundo orden el autor plantea que se deben dar mientras estos no causen daño, ni empobrezcan a quien los da, a la vez que se debe ayudar a aquellos con quienes tenemos lazos estrechos y se encuentran en necesidad.

De la anterior división en la perspectiva ciceroniana se deduce una doble vinculación del ser humano, la primera y más importante es con las instituciones republicanas, por la cual priman los deberes que tenemos para con la república; de esta manera quedan relegados a segundo plano el vínculo que se tiene para con los conciudadanos (hijos, parientes, vecinos) 
y termina excluyendo al extranjero, pues este no se encuentra dentro de los lazos estrechos de los ciudadanos, por lo cual cumplir con el deber de ayuda material es tomado como una forma de empobrecimiento. Por otro lado, se considera que la beneficencia pasa a segundo plano porque el ser que es virtuoso no requiere de la ayuda material, sino que se encuentra sujeto a la providencia como una forma de superación de las pasiones para lograr la eudaimonía.

El cosmopolitismo estoico reconoce la igual valía de todos los seres humanos, fundamentada en la razón que le brinda su cualidad moral. Es por ello mismo que se omiten o pasan en segundo plano las condiciones accidentales tales como el dinero o la posición social, dado que su carencia no impide el florecimiento del ser humano, en tanto que dicha capacidad de florecer tiene su asidero en la dignidad de cada individuo y no en sus posesiones.

Desde la perspectiva de Nussbaum (2020), en la contemporaneidad es moralmente inadmisible mantener dicha división de deberes y es necesario reconocer que los deberes de justicia son a su vez materiales. Es así como las luchas actuales como la abolición de la esclavitud y la tortura deberían ir más allá del reconocimiento de los derechos civiles de las personas y estar acompañados de condiciones materiales que soporten la vida. Ya no se puede aceptar la falsa premisa estoica según la cual la pobreza no atenta contra la dignidad humana y se debe reconocer que los deberes de justicia cuestan, que es necesario invertir recursos económicos que permitan sostener instituciones militares, judiciales, entre otras. Lo anterior, hace que a la vez surja la necesidad de redistribuir riquezas entre las naciones para soportar de esta manera a los países con presupuestos débiles.

\section{Grocio y la ley natural}

Fueron diversas las perspectivas que se dieron en relación con el origen y la instauración de las leyes y las sociedades, entre ellas es muy conocida la constante discusión que tuvo Rousseau en El Contrato Social con los planteamientos de tipo iusnaturalista de dos autores que tuvieron una gran difusión en Europa, a saber: Puffendorf y Grocio. Este último destaca particularmente porque incorpora la tradición al mundo moderno, es decir, vuelve a introducir a la política el ideal humanista que se encontraba presente en la época helénica. El autor plantea la existencia de una ley natural que propende por el respeto por la humanidad, a la vez que reconoce la soberanía nacional y toma al individuo como sujeto de justicia con derechos y plantea que la sociedad internacional se encuentra imbuida en normas morales. 
Entre otras contribuciones que se le reconocen a Grocio se encuentra la sistematización de la tradición y la moralización de las relaciones internacionales debido a que aborda el problema de la desigualdad internacional por medio de una nueva teoría de la propiedad. Ello en medio de un contexto que estaba próximo a la firma de la paz de Westfalia, Holanda perseguía su independencia frente al reino de España y la reforma protestante había introducido el concepto de independencia religiosa, la que a su vez conllevó a consolidar el concepto de autonomía política que terminó repercutiendo en, el ya mencionado, reconocimiento de la soberanía nacional.

Dicho reconocimiento de la soberanía nacional se da debido a la legitimación de la ley al ser resultado de las decisiones de la razón, por lo tanto, demuestran la autonomía de los individuos, grupos sociales y Estados que las promulgan, lo que se convierte a su vez en una exigencia al considerarlas dignas de respeto. De esta manera se empezó a dar pasos hacia la separación entre política y religión, ello debido a dos razones, a saber: los principios morales no dependen de la existencia de una divinidad, a la vez que se dejó de considerar la religión un motivo válido para declarar la guerra.

En cuanto a la comunidad internacional cabe decir que se encuentra regida por la ley moral que surge y fundamenta en la conciencia del individuo, razón por la cual las personas son súbditas de la ley. Claramente Grocio argumenta a favor de la existencia de una ley natural y la demuestra planteando la objetividad de nociones evidentes en el pensamiento humano que nadie puede negar y por medio de las cuales se generan en distintos pueblos legislaciones similares. Sin embargo, ello va a conllevar a una colisión entre el difundido derecho de gentes ius gentium y el derecho natural ius naturale; el primero de ellos es surgido del sentido común por lo cual se caracteriza por ser más laxo que el derecho natural, mientras que el segundo se descubre de una manera más socrática, por lo cual cada uno debe confrontarse individualmente con un proceso de argumentación. Por lo tanto, resurge con Grocio la idea que el hombre posee un razonamiento moral y por lo mismo es capaz de regirse por medio de normas morales naturales.

También cabe destacar que Grocio ataca el derecho de gentes de su época, pues considera que este no respetaba la vida de los inocentes durante el conflicto y por lo mismo plantea que este requiere una reformulación que lo vuelva más moderado en consonancia con el derecho natural, es decir, de acuerdo con normas morales vinculantes que difieran de la ley de su época. En consonancia con ello se puede afirmar que la esfera internacional, en la perspectiva de Grocio, se encuentra enmarcada por una moralidad que trasciende la política, enfoque desde el cual los derechos humanos tienen una existencia pre-política, es decir, estos existen antes que el Estado y 
la legislación. Sin embargo, las instituciones se generan debido a la ley humana que se ve superada por la moral; es por esta misma razón que el establecimiento político gana legitimidad y soberanía pues estas se fundamentan en la dignidad humana.

Dentro de los problemas que aborda Grocio, se encuentra el de las intervenciones humanitarias cuando los Estados Soberanos no protegen los derechos a sus ciudadanos; en este caso el autor examina el origen de los derechos, la soberanía de las naciones no es argumento válido para violar la dignidad humana si estos surgen en la moralidad de los individuos; por otra parte, si los derechos son producto del Estado, se requiere de su soberanía su debido respeto. Esta diferencia repercute en la comprensión de la intervención como una obligación moral o como una afección a la soberanía lo que en últimas se comprende como una agresión a la soberanía de un pueblo y sus ciudadanos. Por ende, el autor plantea que abstenerse de intervenir es una manera de reconocer la falibilidad del juicio y la codicia propia de los Estados. Sin embargo, es necesario intervenir cuando por medio de la violencia se vulneran los derechos de sus ciudadanos, dado que el régimen que se encuentra en el poder se vuelve ilegitimo, si se tiene en cuenta que su legitimidad debería asentarse en la dignidad humana.

\section{Adam Smith y las capacidades humanas}

Mientras en el resto de Europa se daba un gran revuelo, en el Reino Unido Adam Smith en la sexta versión de la Riqueza de las naciones se estaba preguntando por los pilares materiales en pro del funcionamiento humano. El pensador ingles plantea en su texto que la vida se da en medio de condiciones que mutilan y deforman las aptitudes de los seres humanos, de manera que deja ver en su contenido la preocupación por los infortunios de los otros; luego, es necesaria una reflexión en relación con el concepto de dignidad que permita emerger y reconocer las necesidades materiales de las personas.

Smith recupera de Cicerón el concepto de la igualdad cuando se trata de la dignidad de los seres humanos, y replantea la ya conocida separación entre deberes de justicia y de ayuda material o reciprocidad. Encuentra el autor que el núcleo central de la moral ciceroniana es el respeto por la propiedad del otro, pues ello genera que no se promuevan desventajas; lo anterior nos conlleva a la obligación de limitar la satisfacción de nuestros intereses, es decir, trabajar en nuestra capacidad de autodominio. Es por lo mismo que, según el autor, para relacionarnos requerimos de unos acuerdos/pactos que expresen la dignidad humana y, por tanto, la respeten.

Teniendo en cuenta lo anterior, una de las preocupaciones del autor se centra en la importancia del trabajo, pues este permite el desarrollo de las 
habilidades humanas y da forma a las personas. La división de los trabajos genera una diferencia de clases y labores que conllevan a distanciar a las personas por sus capacidades, atentando de esta manera contra la igualdad de las mismas y la libertad de elección en relación con el trabajo, propiedad fundamental de todo ser humano. De hecho, se requiere que la organización económica de las naciones sea una forma de expresión de la dignidad humana y que promueva relaciones respetuosas y recíprocas. Para ello es necesaria la intervención del Estado, por ejemplo, en las economías coloniales y el comercio de esclavos, con el interés de no proteger los negocios de los adinerados.

Por ello los elementos esenciales de la política internacional, en la perspectiva de Smith, son el libre comercio, el fin de la explotación colonial, libertad migratoria y la existencia de un patriotismo cívico. El primero de ellos debe evitar la existencia y propagación de los monopolios, mientras que el segundo promueve la máxima capacidad de autogobierno de quienes habitan en las colonias. A la vez recalca la necesidad de apoyar la comunicación de conocimiento para corregir el desequilibrio de poder. Se requiere de la educación para lograr la transferencia tecnológica a las colonias y el intercambio intelectual con las mismas. En relación con la migración el autor planteó la necesidad de apoyar la libertad de movimiento de los trabajadores para hallar empleo y con ello evitar la ya mencionada desigualdad de capacidades al no tener las posibilidades de desplazarse al lugar donde puede florecer su trabajo.

Sin embargo, cabe resaltar que en el pensamiento del autor se da cabida al surgimiento de la necesidad de condiciones materiales para la existencia de una vida digna; es decir, Smith pone de manifiesto que, en oposición con Cicerón, para el florecimiento de la vida al igual que unas condiciones racionales y morales propias del ser humano, son también necesarias las condiciones materiales que habían sido rechazadas por el cinismo y el estoicismo. Desde la perspectiva de Nussbaum (2020), ello se debe a una posición que se encuentra velada en las actitudes de resignación y resistencia propias de estas escuelas filosóficas que a la postre terminan reflejando un sentimiento de virilidad. Adicionalmente, la filósofa estadounidense encuentra en esta posición la posibilidad de solucionar problemas que presenta la tradición como lo son: la separación de los deberes de justicia y ayuda material y con ello la idea que los bienes materiales no influyen en las posibilidades de florecimiento de la vida. 


\section{Martha Nussbaum: de la educación cosmopolita al enfoque de las capacidades}

En el capítulo sexto de La tradición cosmopolita, Martha Nussbaum plantea la existencia de cinco problemas contemporáneos que requieren ser abordados por el cosmopolitismo, a saber: primero, la necesidad de desarrollar una psicología moral que sea realista respecto de los límites humanos y que teorice emociones tales como el miedo, la ira y la envidia. Por lo cual, la autora considera necesario describir las raíces del prejuicio para superar problemas como la exclusión y la xenofobia. El segundo y tercer problema giran en torno a la necesidad de plantear unos principios políticos/ morales razonables en los que se permita la libertad religiosa y el respeto de los derechos de todas las personas. Se debe rechazar la perspectiva del cosmopolitismo como una ética comprensiva universalista, punto de vista desde el cual se pretendía rechazar la religión tradicional; esto se debe superar por medio de la promoción de la laicidad del Estado y de unas leyes neutras, es decir, que sean principios aceptables para todos. Por lo anterior se debe comprender el derecho internacional como un ámbito moral que trasciende el plano jurídico sin que ello socave la soberanía de las naciones. En cuarto, se reconoce el problema que implica la ayuda exterior, pues esta canalizada por medio de las ONG mina la capacidad de acción de los Estados, lo que a su vez debilita la voluntad política del pueblo y los gobernantes para la creación de instituciones.

El último problema planteado por la filósofa estadounidense es el del asilo y la migración, y sobre este plantea: "el respeto por la humanidad nos obliga a facilitar de algún modo el sustento elemental para la vida humana de aquellos que sufren una situación de necesidad desesperada" (Nussbaum, 2020, p. 246); razón por la cual retoma el planteamiento de Grocio según el cual es necesario reconsiderar el concepto de propiedad, pues esta puede ser tomada legítimamente por aquel quien la necesita. Sin embargo, es necesario decir que, si bien la autora desglosa el problema de la migración, el asilo a personas refugiadas y los problemas morales que implica el programa de trabajadores invitados desembocan en su propuesta del enfoque de capacidades que, al parecer, no desarrolla a plenitud.

La filósofa estadounidense Martha Nussbaum ha planteado entre sus trabajos, la necesidad de una educación de carácter cosmopolita; ella comprende el cosmopolitismo como una respuesta moral de apreciación del multiculturalismo, ante lo cual es necesaria una educación global más comprensiva sobre las culturas del mundo con el fin de reconocer los valores, creencias o prácticas de diversas comunidades. 
Sin embargo, en su más reciente obra La tradición cosmopolita (2020) se hace explícito el viraje de su trabajo y el planteamiento de una nueva propuesta para abordar el proyecto cosmopolita que atienda directamente a las posibilidades de florecimiento de toda vida humana en la clásica perspectiva de la moralidad; a la vez se preocupa también por las condiciones materiales necesarias para este fin. Por ello, plantea el enfoque de las capacidades pues considera que "el EC aborda directamente el meollo de la cuestión (de las necesidades materiales) al subrayar que todos los derechos tienen un aspecto económico y social, y que no existe forma congruente alguna de separar los deberes de justicia de los deberes de ayuda material" (Nussbaum, 2020, p. 253). Esta propuesta originalmente planteada por Amartya Sen pretende afincarse como nuevo criterio para establecer comparaciones de bienestar entre las naciones. Comúnmente son usados enfoques que tienen como referentes los recursos, por ejemplo, el PIB o en el indicador de satisfacción de preferencias. Lamentablemente estos enfoques carecen de neutralidad y terminan siendo favorables a quienes ya cuentan con los recursos por lo cual enmascaran problemas como las grandes desigualdades internas en países con altos índices de desarrollo.

Nussbaum diferencia entre tres tipos de capacidades, básicas o innatas de las personas, internas o adquiridas por medio de la crianza recibida y las capacidades combinadas, las cuales se entienden como aquellas adquiridas por el proceso educativo a las que se les añade condiciones externas que posibilitan a la persona tener libertad para elegir. La autora propone diez capacidades que han de ser protegidas para que una nación pueda considerarse justa, las cuales se listan a continuación:

- Vida de duración normal.

- Mantener buena salud.

- Protección a la integridad física.

- Educación adecuada.

- Desarrollo emocional.

- Planificar la propia vida.

- Participación e interacción social.

- Relación con el mundo natural.

- Disfrutar de actividades recreativas.

- Control del entorno político y económico.

Finalmente, según Nussbaum, el enfoque de las capacidades pone el énfasis en que la protección de los derechos cuesta dinero y, por lo tanto, es necesario reconceptualizar la común clasificación de los derechos humanos que hace una separación entre civiles -primera generación- y los sociales / 
económicos- segunda generación. Desde esa perspectiva habría de tenerse claro que todos los derechos son económicos por extensión, pues implican que todos los países deben invertir sus recursos monetarios para cumplir con las obligaciones y condiciones adecuadas de vida que implica la dignidad humana.

\section{Referencia bibliográfica}

Nussbaum, M. C. (2020). La tradición cosmopolita. Un noble e imperfecto ideal. Ediciones Paidós. 